Supplement of Atmos. Meas. Tech., 12, 2949-2966, 2019

https://doi.org/10.5194/amt-12-2949-2019-supplement

(c) Author(s) 2019. This work is distributed under

the Creative Commons Attribution 4.0 License.

(c) (1)
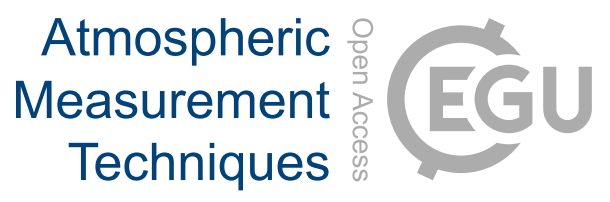

Supplement of

\title{
Quantification of $\mathrm{CO}_{2}$ and $\mathrm{CH}_{4}$ emissions over Sacramento, California, based on divergence theorem using aircraft measurements
}

Ju-Mee Ryoo et al.

Correspondence to: Ju-Mee Ryoo (ju-mee.ryoo@nasa.gov)

The copyright of individual parts of the supplement might differ from the CC BY 4.0 License. 
(a)

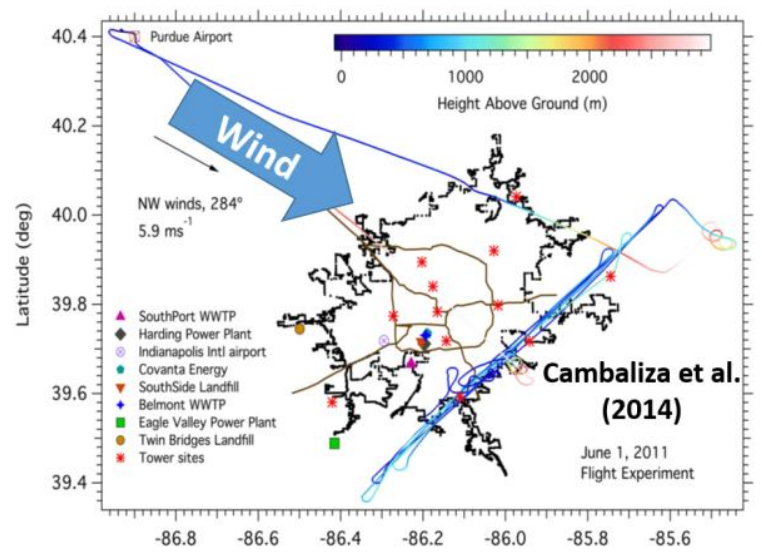

(b)

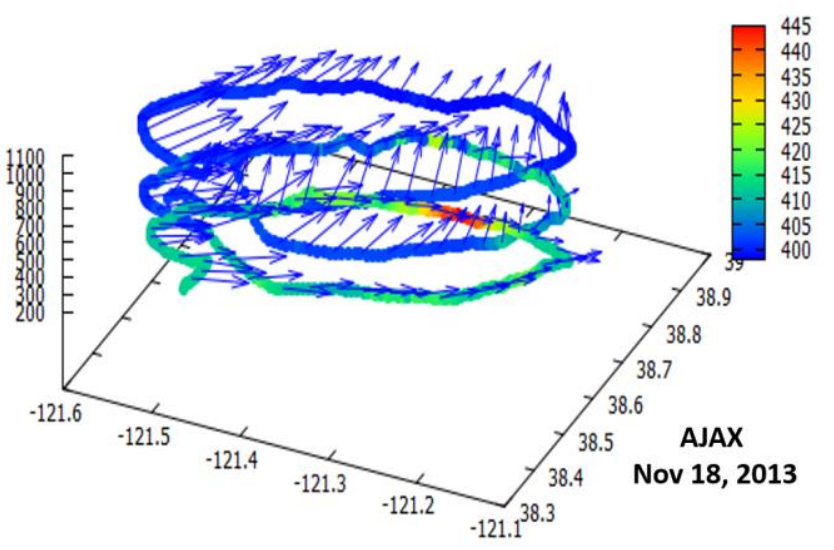

Figure S1: Comparison of flight design: (left) conventional curtain flight and (right) the cylindrical flight track. The arrows overlaid over the cylinder represent the 3-D wind measured in-situ.

Figure S1a shows the typical mass balance "curtain flight," which detects point sources and assumes that emissions are accumulated downwind. This typical flight pattern requires the prior knowledge of wind direction because this can be a critical factor in deciding where to measure. This flight pattern also ignores the vertical mass transfer from the top of the Planetary Boundary Layer (PBL) and the surface. In contrast, Fig. S1b shows the same mass balance approach in conjunction with a cylindrical flight pattern. Using this method, we can detect emissions from more than one point source within a city, both downwind and throughout the city. Also, while useful for planning, prior knowledge of wind direction is not necessary for measurements. Lastly, vertical mass transfer across the top and bottom of the cylinder can be estimated using this approach.

To see the effect of wind conditions on the measurements, we looked at the wind direction and its change with altitude on November 18 in Fig. S1b. On November 18, 2013, the wind was primarily southerly or southeasterly; over the downwind northwestern segment, the $\mathrm{CO}_{2}$ mixing ratio tended to be elevated in the lower altitude. This flight illustrates that the wind can vary by altitude and location, even if measured on the same day within the same hour, or within a few kilometers. Therefore, relying on an assumption of "constant" regional or continental scale wind throughout the entire range of altitudes can produce biased flux estimates. 


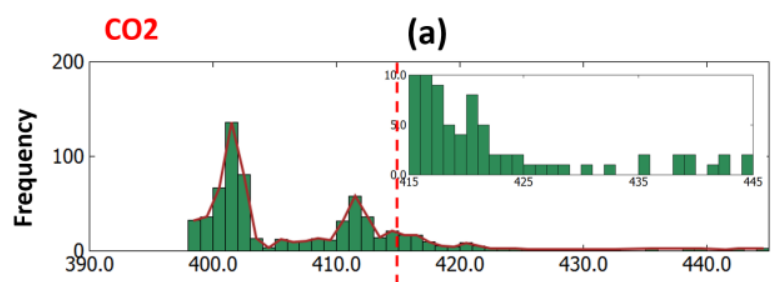

(c)

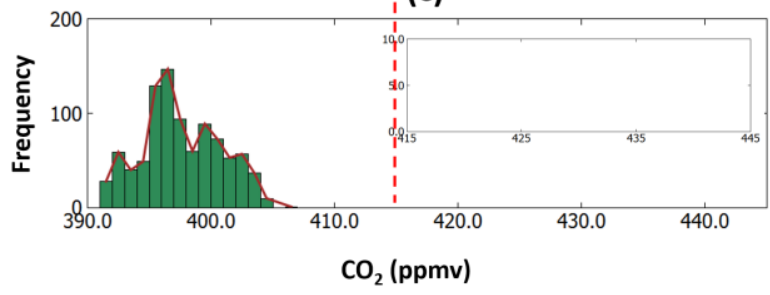

(b)

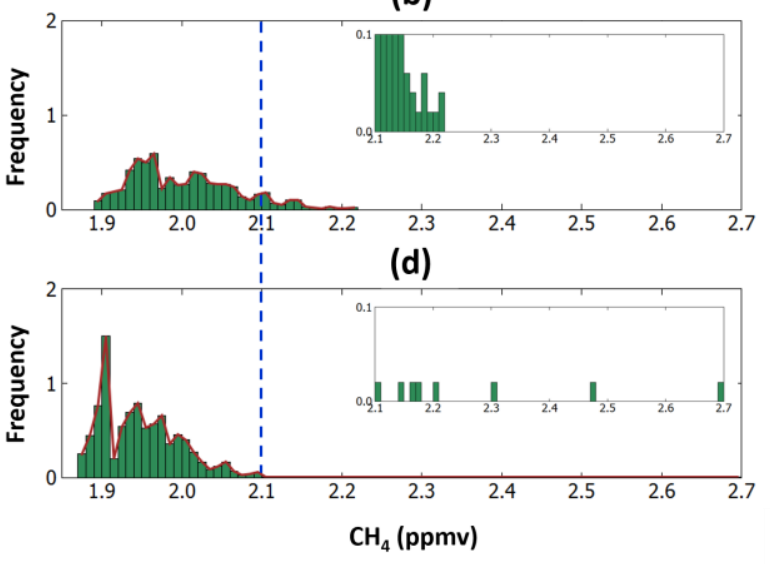

Figure S2: The probability distribution functions of (left) $\mathrm{CO}_{2}$ and (right) $\mathrm{CH}_{4}$ mixing ratio over the whole Sacramento on (a, b) November 18, 2013, (c, d) July 29, 2015. The insets expand the vertical axis as indicated by the dashed lines. Measurement over the entire urban area of Sacramento is used for both flight days here.

Figure S2 displays the probability distribution functions (histograms) of observed (left) $\mathrm{CO}_{2}$ and (right) $\mathrm{CH}_{4}$. Both $\mathrm{CO}_{2}$ and $\mathrm{CH}_{4}$ for the winter flight shows bimodal patterns, highlighting the difference between upwind and downwind sides of the city. But on the July 29 flight, there is also an "intermediate" region of high average $\mathrm{CH}_{4}$ mixing ratio. $\mathrm{CO}_{2}$ mixing ratio was greater in winter (November) than in summer (July), but no significant difference was found for $\mathrm{CH}_{4}$. The highest $\mathrm{CO}_{2}$ values (> 415 ppmv) were only observed in winter, but the $\mathrm{CH}_{4}$ values (>2.1 ppmv) were found during both summer and winter. Although caution is required while ascribing "seasonality" to the $\mathrm{CO}_{2}$ data from just two months, the seasonality implied is consistent with the previous studies and with the general characteristics of the $\mathrm{CO}_{2}$ seasonal cycle (Dettinger and Ghil, 1998; Pataki et al., 2003). 
(b)

(a)

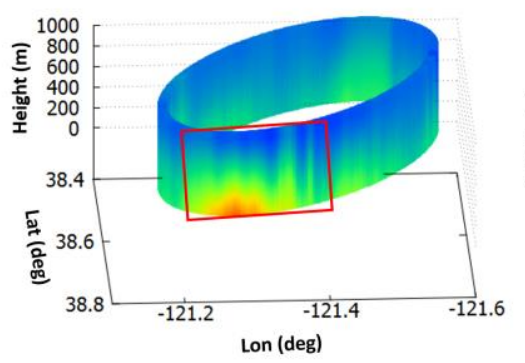

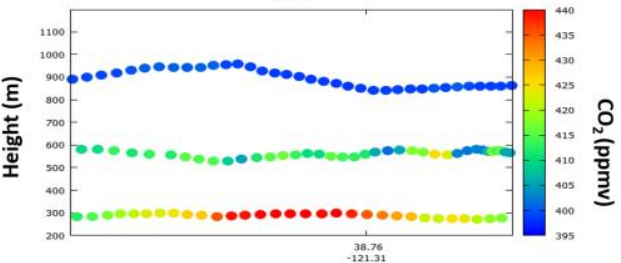

(c)

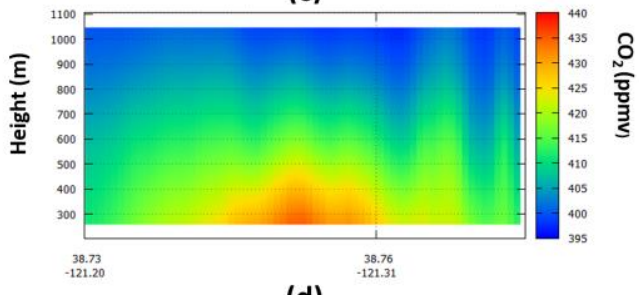

(d)

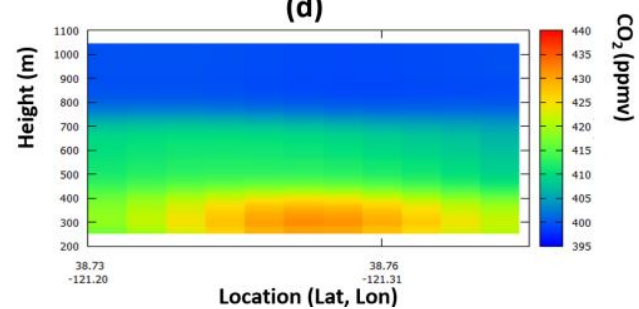

Figure S3: (a) Kriged $\mathrm{CO}_{2}$ mixing ratio, (b) Measured $\mathrm{CO}_{2}$ mixing ratio, (c) $\mathrm{CO}_{2}$ mixing ratio using kriging interpolation method, (d) interpolated $\mathrm{CO}_{2}$ mixing ratio using a conventional exponential weighting function along a subset of the ellipse around Sacramento on November 18, 2013. This portion of the perimeter corresponds to the red box of the elliptical cylinder shown in panel a. The vertical extent of the elliptical and 2-D plots is set to the highest measurement altitude.

Figure $\mathrm{S} 3$ shows the observed $\mathrm{CO}_{2}$ mixing ratio obtained by AJAX for a portion of the ellipse sampled in 2013, and the interpolated $\mathrm{CO}_{2}$ mixing ratio calculated using ordinary kriging or an exponential weighting function. The interpolated value using the exponential weighting function is defined as the value at each point $(\mathrm{P})$ as the weighted average of all the other points, where the weight of each decreases exponentially with its distance to P. Both interpolation methods captured the general plume pattern (high and low concentration of $\mathrm{CO}_{2}$ regions), but kriging interpolation did a better job in capturing the individual plume characteristics such as range and magnitude. 

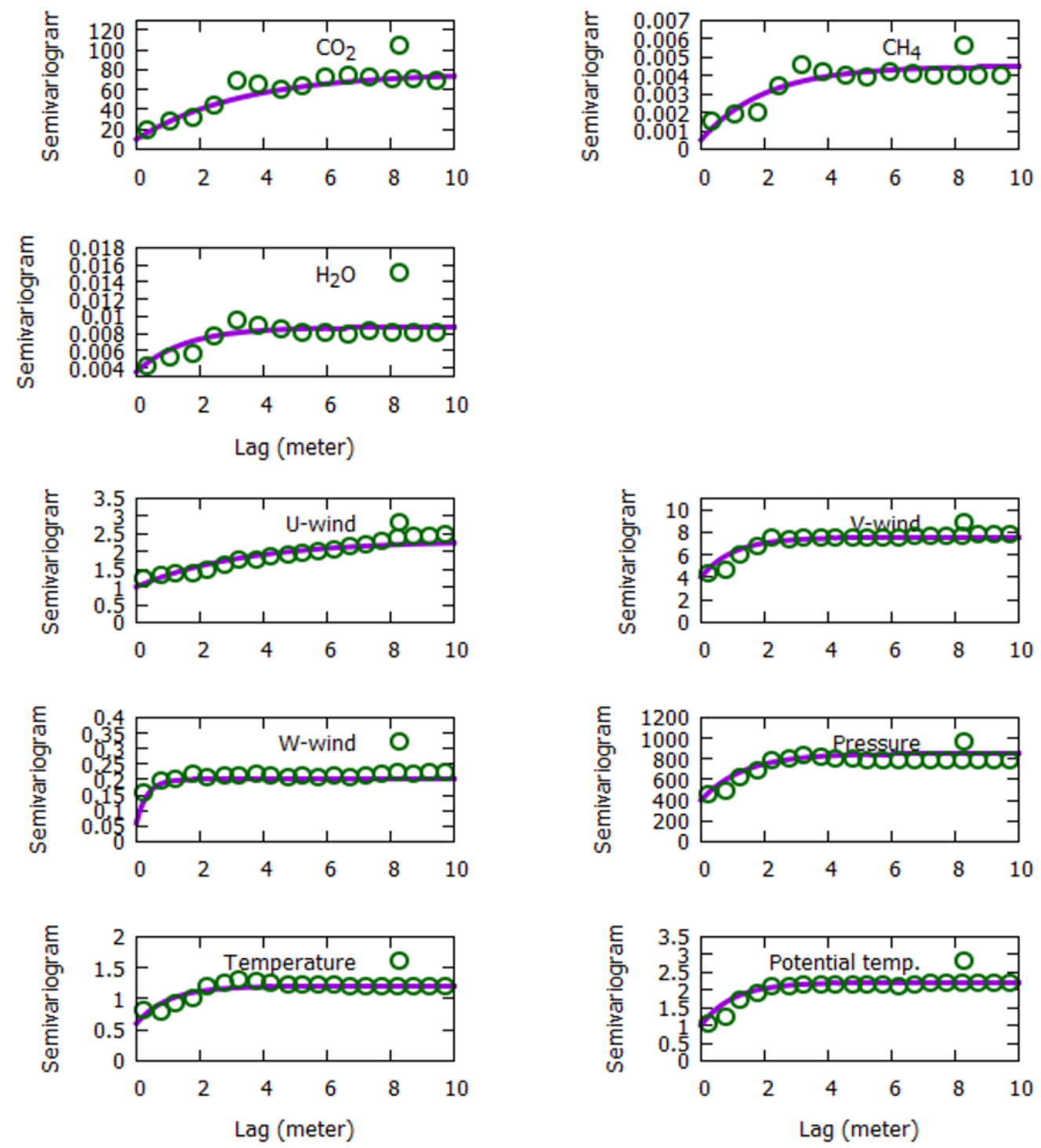

Figure S4: The experimental (open circle) and theoretical exponential (solid purple line) semivariograms of $\mathrm{CO}_{2}, \mathrm{CH}_{4}$, $\mathrm{H}_{2} \mathrm{O}$, 3-D winds ( $\left.\mathrm{U}, \mathrm{V}, \mathrm{W}\right)$, pressure, temperature, and potential temperature for the flight on November 18, 2013. 
(a)

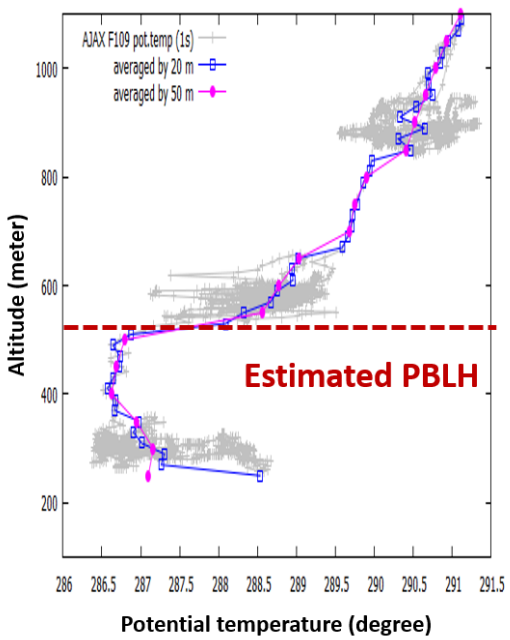

(b)

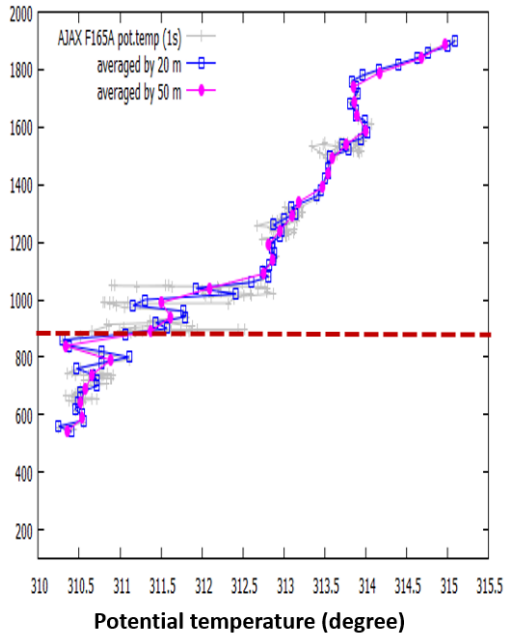

(c)

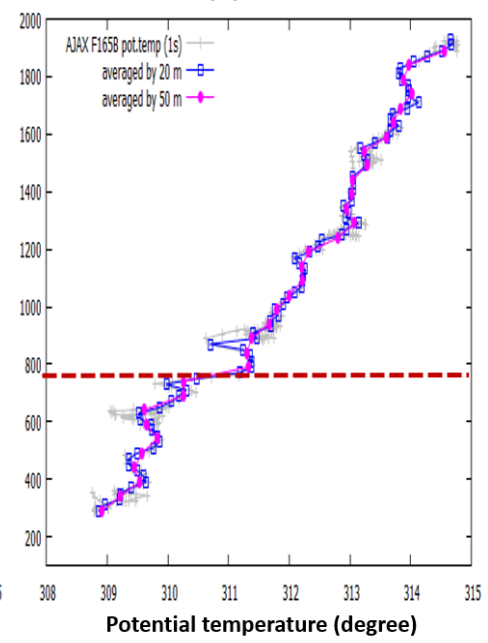

Figure S5: Potential temperature collected on (a) November 18, 2013 and (b, c) July 29, 2015. Panel (a) shows data collected over the urbal scale sacramento region, while panels $(b, c)$ shows data collected in a spiral over the local scale landfill, and the rice field, respectively. The dashed line indicates the estimated planetary boundary layer height (PBLH), identified by the maximum gradient of the potential temperature. 


\section{Local scale $(<3 \mathrm{~km})$ - Small loops on July 29, 2015}

To find the contribution from two local sources of particular importance, small loops ( $\sim \mathrm{Z} \mathrm{km}$ in diameter) were flown over a landfill and a rice field shown in Fig. 7. The measured $\mathrm{CO}_{2}$ and $\mathrm{CH}_{4}$ mixing ratios over two local regions are shown in Fig. S6. The enhancements of $\mathrm{CO}_{2}$ and $\mathrm{CH}_{4}$ were not collocated, indicating different point sources. For both $\mathrm{CO}_{2}$ and $\mathrm{CH}_{4}$, larger mixing ratios were detected over the landfill. It has been known that landfills are large contributors to $\mathrm{CH}_{4}$ emissions (Mays et al. 2009). Due to the photosynthetic activity of plants during summer, $\mathrm{CO}_{2}$ over the rice field appears to be low. The wind direction was mostly easterly or southeasterly over the landfill and mostly southerly over the rice field. The wind speed was weaker over the landfill $\left(\right.$ mostly $\left.<4 \mathrm{~m} \mathrm{~s}^{-1}\right)$ than that over the rice field, indicating that most of the methane observed over the landfill originated from that source.

(a)

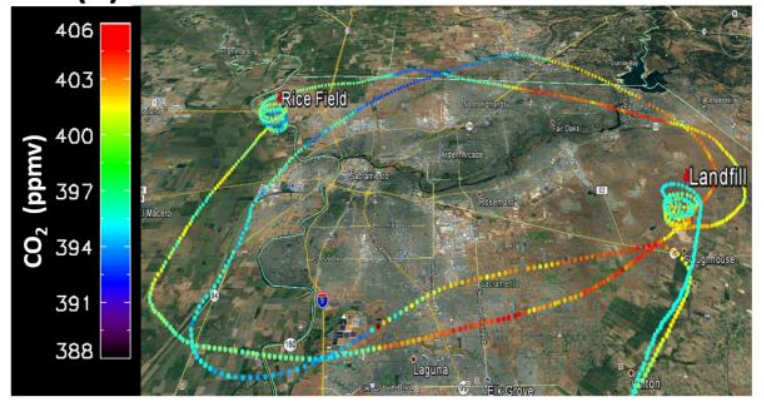

(c) (b)

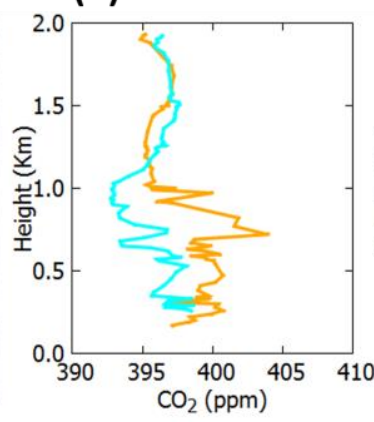

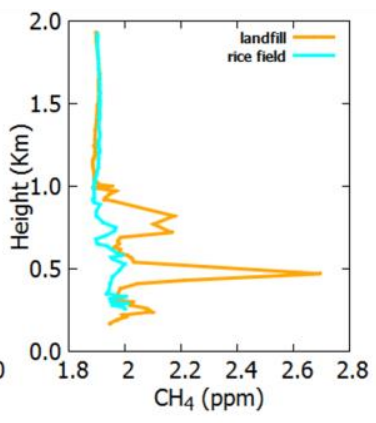

(d) $\begin{aligned} & y=-11.6+0.0342 \times(r=0.694) \\ & y=-3.01+0.0124 \times(r=0.634)\end{aligned}$

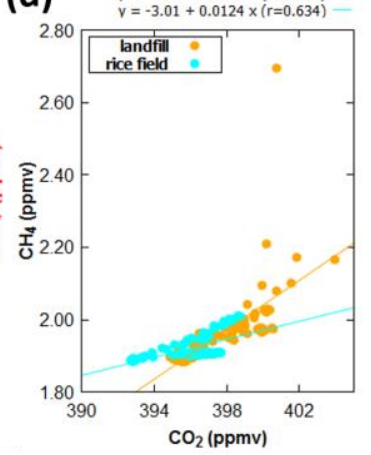

Figure S6: (a) Map of $\mathrm{CO}_{2}$ mixing ratio over Sacramento with two local sites (landfill, rice field). (b) Vertical profiles of $\mathrm{CO}_{2}$ and $\mathrm{CH}_{4}$ mixing ratios. (c) Time series of altitude (gray), $\mathrm{CO}_{2}$ (blue) and $\mathrm{CH}_{4}$ (red) mixing ratio, and (d) correlation of $\mathrm{CO}_{2}$ and $\mathrm{CH}_{4}$ over (red) landfill, and (blue) rice field in Sacramento, CA on July 29, 2015. The shaded portions (orange and cyan) highlight the vertical profiling at two local sites. 